\section{References}

1. Siegel, R. W., Ramasamy, S., Hahn, H., Zongquan, Li, Ting, Lu, Gronsky, R. (1988). Synthesis, Characterization, and Properties of Nanophase $\mathrm{TiO}_{2}$. Journal of Materials Research, 3 (6), 1367-1372. doi: 10.1557/jmr.1988.1367

2. Karroll-Porchinskiy, Ts. (1966). Materials of the future. Heat-resistant and heatproof fibers and fibred materials. Moscov, Khimiya, 237.

3. Suyama, Y., Kato, A. (1976). $\mathrm{TiO}_{2}$ produced by vaporphase oxygenolysis of $\mathrm{TiCl}_{4}$. Journal of the American Ceramic Society, 59 (3-4), 146-149.

doi: 10.1111/j.1151-2916.1976.tb09453.x

4. Tretyakov, Yu. D. (2006). Mykro- and nanoworld of modern materials Moscov, MGU, 69.

5. Weibel, A., Bouchet, R., Denoyel, R., Knauth, P. (2007). Hot pressing of nanocrystalline $\mathrm{TiO}_{2}$ (anatase) ceramics with controlled microstructure. Journal of the European Ceramic Society, 27 (7), 2641-2646.

doi: 10.1016/j.jeurceramsoc.2006.11.073

6. Knauth, P., Bouchet, R., Schaf, O., Weibel, A., Auer, G. (2002). Functionalized $\mathrm{TiO}_{2}$ nanoparticles for pigments, photoelectrochemistry, and solid state chemical sensors. Synthesis, Functionalization and Surface Treatments of Nanoparticles, ed. M.-I. Baraton. American Science Publications, Stevenson (Chapter 8).

7. Shaporev, V. P., Krasnikova, L. A., Tkach, G. A. (1991). Patent of USSR № 1649851. MKI C 30 B 9/12, 23/62, 29/22. The method of whiskering titian's of alkaline threw a catch and refractory oxides. Application number 46186305/28 1988.13.12, application date: January 15, 1991 (for the official use).

8. Shaporev, V. P., Krasnikova, L. A., Tkach, G. A. (1990). Patent of USSR № 1619756. MKI C 30 B 29/62, 29/32, 9/00. Device for the whiskering. Application number 4653751 1989.23.02, application date: September 8, 1990 (publication forbidden).

9. Shaporev, V. P. (1994). Technology of inorganic reinforcing fillers. Kharkov state polytechnic institute, Kharkiv, Ukraine, 365.

10. Shaporev, V. P., Sebko, V. V. (2012). About possibilities of application of methods of nano-chemistries for the analysis and intensification of chemical technological processes. Visnyk NTU «KhPI», 61 (967), 164-176.

11. Norrish, K. (1951). Priderite, a new mineral from the leucite-lamproites of the west Kimherley area, Western Australia. Mineralogical Magazine, 29 (212), 496-501. doi: 10.1180/minmag.1951.029.212.03

12. Pring, A., Jefferson, O. A. (1983). Incommensurate superlattice ordering in priderite. Mineralogical magazine, March 47, 65-68. doi: 10.1180/minmag.1983.047.342.11

13. Pryce, M. W., Hodge, L. C., Griddle, A. J. (1984). Griddle Jeppeite, a new K-Ba-Fe titanate from Walgidee Hills, Western Australia. Mineralogical magazine, 48 (347), 263-266. doi: 10.1180/minmag.1984.048.347.11

14. Povarennykh, A. S. (1966). Crystals chemistry classification of mineral prospects. Kiev, Naukova Dumka, 547.

15. Bokiy, G. B. Crystals chemistry. Moscow, Nauka, 400. Дата надходження рукопису 10.12.2014

Шапорев Валерий Павлович, доктор технических наук, профессор, кафедра химической техники и промышленной экологии. Национальный технический университет «Харьковский политехнический институт», ул. Фрунзе, 21, г. Харьков, Украина, 61002

E-mail: fiola2008@mail.ru

Шестопалов Алексей Валерьевич, кандидат технических наук, доцент кафедры химической техники и промышленной экологии, Национальный технический университет «Харьковский политехнический институт», ул. Фрунзе, 21, г. Харьков, Украина, 61002

E-mail: pheonix_alex@mail.ru

Питак Инна Вячеславовна, кандидат технических наук, доцент кафедры химической техники и промышленной экологии, Национальный технический университет «Харьковский политехнический институт», ул. Фрунзе, 21, г. Харьков, Украина, 61002

E-mail: ipitak5@gmail.com

УДК 656.212.2:004.353.24

DOI: 10.15587/2313-8416.2015.35869

\title{
ВИКОРИСТАННЯ МЕТОДІВ АНАЛІЗУ ВІДЕОЗОБРАЖЕННЯ ДЛЯ КОНТРОЛЮ РОЗПУСКУ НА СОРТУВАЛЬНИХ ГІРКАХ. ЧАСТИНА 1
}

\section{(C) І. М. Сіроклин, А. А. Бражник, В. О. Фоміна}

В роботі виконано огляд найбільш поширених методів аналізу відеозображення для виявлення руху на нерухомому фоні. Отримані результати проаналізовано з точки зору можливості контролю розпуску рухомого складу на сортувальних гірках. Для реалізації поставленої задачі застосовано метод віднімання фону. Для апробації результатів використано відеозаписи розпуску відчепів на сортувальній гіриі Одеса-сортувальна Ключові слова: аналіз відеозображення, виявлення руху відчепів, сортувальна гірка, контроль ділянок колї

A review of the most common video image analysis methods for detect motion in a stationary background is done in this article. The results are analyzed in terms of the ability to detaching control of rolling stock on hump yards. The background subtracting method is used for realization of this problem. The video of cuts detaching on OdesaSortuvalna hump yards are used for test the results

Keywords: video analysis, cuts motion detection, hump yard, track section control

\section{1. Вступ}

Дослідження, направлені на удосконалення мето- дів аналізу відеозображення, мають значну актуальність, оскільки потенційно можуть замінити велику 
кількість технічних засобів, що нині експлуатуються в комплексі систем автоматики і телемеханіки залізничного транспорту.

Як приклад розглядається автоматичний відеоконтроль коректної роботи системи ГАЦ, або контроль заповнення колій сортувального парку. Такі підходи цілком можливо використовувати як доповнення до існуючих систем.

Мета роботи - огляд найбільш поширених методів аналізу відеозображення для виявлення руху на нерухомому фоні з метою контролю розпуску рухомого складу на сортувальних гірках. Огляд результатів застосування методу віднімання фону.

\section{2. Постановка задачі}

Комплекс технічних засобів для автоматизації технологічних процесів на сортувальних гірках включає в себе різноманітні варіації рейкових кіл, точкові датчики, фотоелектричні та радіотехнічні датчики, пристрої контролю заповнення колії, вагоміри, швидкостеміри, пристрої контролю розчеплення та інші. Кожен 3 перелічених пристроїв являє собою елемент системи автоматизації, що направлена на ефективне виконання процесу розпуску рухомого складу. Кожен з перелічених пристроїв має свою досить вузьку сферу використання і свої недоліки, що вимагає додаткових технічних засобів для їх компенсації.

Натомість достатньо кваліфікований черговий по гірці здатний вести розпуск, спираючись переважно на візуальну інформацію спостереження за процесом розпуску. Відтак, аналіз відеозображення дає достатній обсяг інформації для формування рішення щодо необхідної швидкості розпуску, ходових характеристик відчепа та відповідності руху відчепа його завданню.

\section{3. Літературний огляд}

Відомий досить широкий спектр досліджень, направлених на використання методів аналізу відеозображення у сфері залізничного транспорту. Так, у роботах $[1,2]$ розглянуто використання автоматичного аналізу відеозображення для ідентифікації небезпечних ситуацій на переїздах. Передбачено аналіз змін зображення відносно відомого фону (опорної матриці). Ідентифікація небезпечних ситуацій спирається на попередню обробку опорного зображення, моделювання та визначення руху i, нарешті, - кінцева обробка інформації для визначення ступеня небезпечності руху.

Такий підхід вимагає скорочення обсягу інформації, яка надходить, і усереднення значень пікселів. Слід також зазначити, що виникає необхідність перевести відеоряд у півтони, щоб регулювати яскравість пікселів як показників зони порівнювання початкового зображення.

Метод фіксованого фону найбільш швидкодіючий, але вимагає постійного оновлення опорного зображення, оскільки такий метод чутливий до незначних змін загального фону. Часто при моделюванні фіксуються несуттєві деталі, які відрізняються від початкового зображення, що суттєво погіршує якість ідентифікації рухомого складу.

Роботи [3, 4] передбачали отримання відеозображення з рухомого об'єкта, щоб забезпечити безпеку пересування рухомого складу. Для того щоб розшири- ти фунціональні можливості, в роботах розглядається використання технологій комп'ютерного зору, що дало змогу вести цілодобовий аналіз видової інформації залізничної колії в режимі реального часу. Якщо під час руху була виявлена небезпека (пошкодження поверхні рейок або невідповідність сигналу колійного світлофора), машиністу подається відеозображення і сигнал для детального аналізу видової обстановки.

Для контролю розпуску рухомого складу на сортувальних гірках такі дослідження становлять інтерес 3 точки зору ідентифікації небезпечних ситуацій, а також адаптації системи розпізнавання до зміни освітлення та різноманітних кліматичних умов.

Ідентифікація рухомих об'єктів на нерухомому фоні $є$ предметом досліджень суміжних сфер народного господарства $[5,6]$. Значні досягнення у сфері застосування відеоконтролю та автоматичного аналізу відеозображення отримані в авіаційній галузі.

Джерела [7, 8] містять дослідження, в яких розглядаються комп'ютерні моделі фоноцільової обстановки і програми, що реалізують алгоритм безперервного супроводу мерехтливого точкового об'єкта, що рухається, з обчисленням картинних координат X i Y об'єкта, що відстежується.

Інтерес становлять методи прогнозу поведінки об'єкта. Представлена авторами модель [8] демонструвала високу ефективність супроводу цілі на тлі інтенсивної шумової складової, що має статистичні характеристики, які практично збігаються з характеристиками об'єкта, і можливість супроводу до 1000 цілей у секунду при користуванні бортового процесора, побудованого відповідно до цієї моделі.

У багатьох способах інтеграції інформації від бортових систем технічного зору літального апарата поставали питання 3 виникнення та компенсації геометричних спотворень зображень.

Технології поліпшення і комплексування теле- i тепловізійних зображень, а також способи поєднання радіолокаційних, теле- і тепловізійних зображень та цифрової карти місцевості були вирішені за допомогою систем покращуваного і синтезованого зору [9-11]. Результатами роботи цих систем стало синтезоване зображення, на якому максимально ефективно і повно відображена уся інформація про навколишній стан (рельєф, статичні та динамічні об'єкти з певними характеристиками).

4. Використання методу віднімання фону та апробація результатів досліджень

В результаті проведеного аналізу досліджень і публікацій визначено, що типовими підходами до визначення руху об'єктів на нерухомому фоні є метод виділення фону, метод міжкадрової різниці, метод віднімання фону, методи моделювання фону.

Усі методи чутливі до різних шумів і зміни освітлення, але метод міжкадрової різниці і метод виділення фону є більш стійкими. Проте вищеперелічене не може надати високої точності результатів, на відміну від методу віднімання фону. Розглянемо цей метод i результати його застосування для ідентифікації рухомих об'єктів на сортувальних гірках.

Насправді існує багато алгоритмів цього методу, але майже всі вони складаються 3 одних і тих самих 
процедур (рис. 1). Найголовнішими є передобробка, моделювання фону, виявлення руху і постобробка.

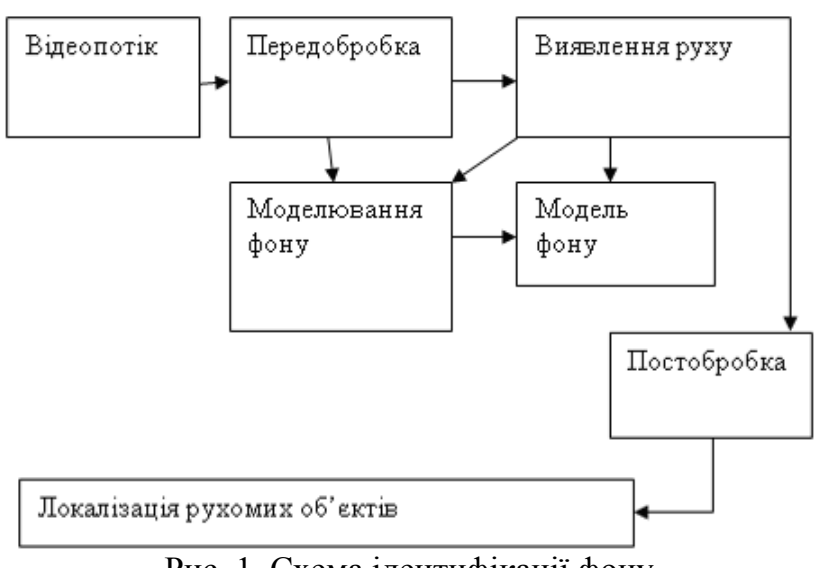

Рис. 1. Схема ідентифікації фону

Розглянемо етапи більш детально, почнемо з передобробки. Основним завданням є підготовка зображення до виявлення на ньому рухомого об'єкта. Тому даний етап має зводитися до виділення на зображенні тих елементів, які, припустимо, належать до рухомих об'єктів. Ми приймаємо за рухомий об'єкт те, що людський зір сприймає таким, спостерігаючи один за іншим кадр відеопотоку.

Першою дією на даному етапі буде зменшення розміру кадру, що надасть важливу перевагу у вигляді скорочення обсягу інформації, яку необхідно обробляти на кожному етапі. По-іншому цей крок можна назвати усередненням значень пікселів, оскільки значення яскравості вихідного пікселя будуть замінюватися середнім значенням даної яскравості і сусідньої. Результуючий піксель $є$ мінімальною зоною початкового зображення.

Крок другий - перетворення формату зображення. Характеристикою пікселя є яскравість, яка використовується при відніманні фону, тому нам необхідно переводити відеоряд у напівтонові зображення.

Приклад напівтонового зображення відео 3 сортувальної гірки можна побачити на рис. 2.

У системі MatLab відеопотік можна переконвертувати в послідовність напівтонових зображень, або формат YCbCr (Y -компонента яскравості, CB i CR синя і червона кольорорізницеві компоненти).
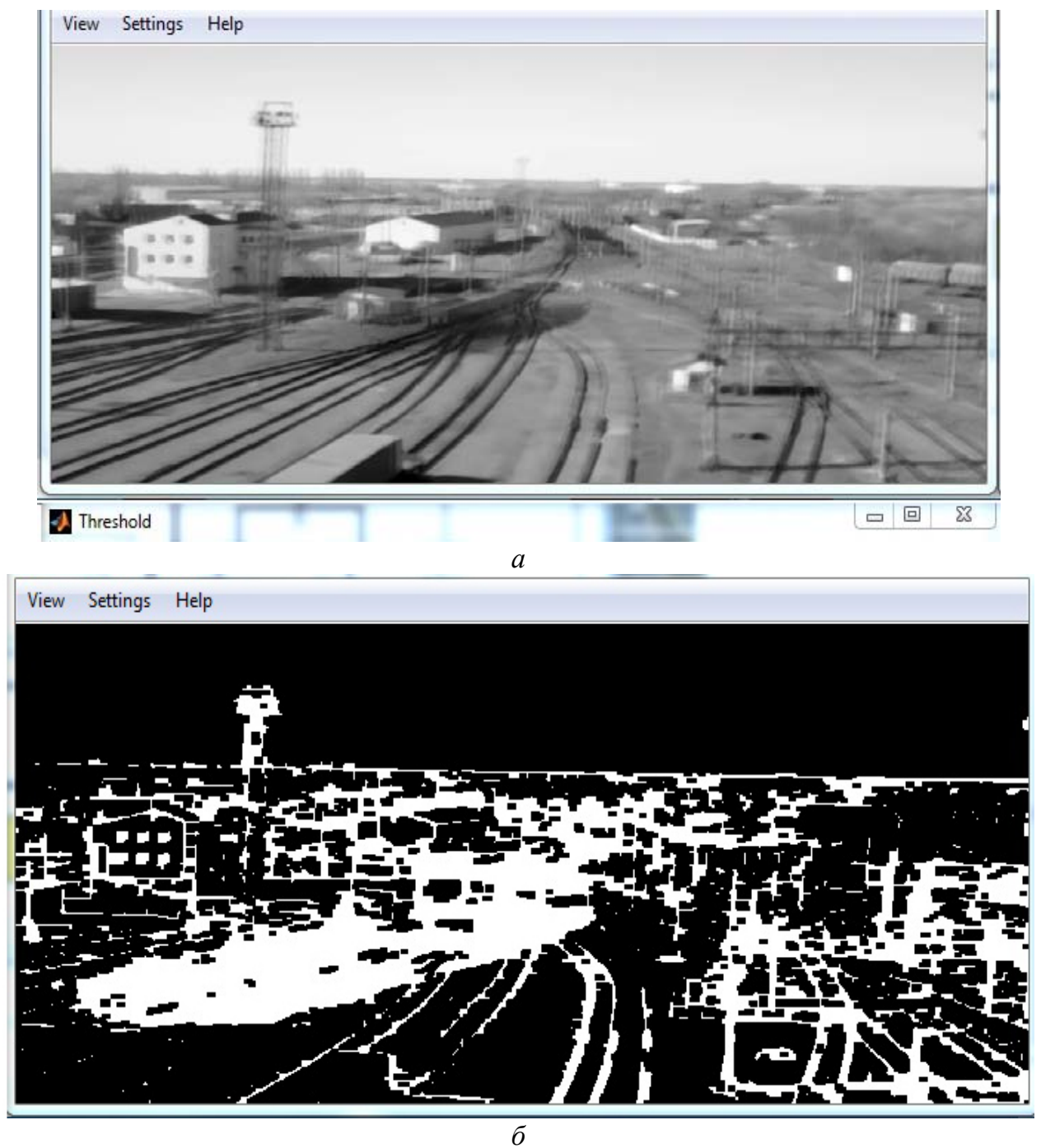

Рис. 2. Послідовність напівтонових зображень: $a$ - напівтонове зображення; $\sigma$ - бінарне зображення фону

Тепер - моделювання фону. Цю задачу можна виконати одним із двох методів: методом фіксованого фону або усередненням.

Існує два варіанти використання фіксованого 
фону. У цьому методі перший кадр буде фоном. Алгоритм збереже перший кадр у відеопослідовності, а потім для кожного наступного буде примірювати поріг до модуля різниці поточного та збереженого зображення по кожному пікселю.

Мінус першого методу - сувора вимога до однорідності фону, яку важко виконати в нашому випадку. Тоді можна моделювати фон методом усереднення 3 невеликою кількістю (30-100) послідовних кадрів відеопотоку. У цьому методі моделлю фону буде середнє від перших n-кадрів:

$$
B G(x, y)=\frac{1}{n} \times \sum_{i=1}^{n} \operatorname{Ii}(x, y),
$$

де $B G$ - основний фон; $I$ - кадр.

Наш алгоритм має бути стійким до зміни фону (наприклад, освітлення, погодних умов), тому нам необхідно оновлювати фон у перебігу часу, грунтуючись на початковій моделі фону.

Має сенс розглянути «Наближений медіанний метод». Наближений медіанний метод схожий з методом середнього значення. Для підраховування фону використовується формула:

$$
B G_{i}(x, y)=\left\{\begin{array}{l}
B G_{i-1}(x, y)+\delta, \text { якщо } I_{i}(x, y)<B G_{i-1}(x, y), \\
B G_{i-1}(x, y)-\delta, \text { якщо } I_{i}(x, y)>B G_{i-1}(x, y), \\
B G_{i-1}(x, y)-\text { в інших випадках, }
\end{array}\right.
$$

де $B G_{i}(x, y)$ - основний фон головного кадру; $B G(t-l)-$ фон іншого кадру; $\delta$ - задане значення, яке не повинно бути дуже малим.

Інший метод - рекурсивного згладжування, який передбачає плавну зміну моделі фону 3 кожним кадром, застосовуючи низькочастотний фільтр. Реалізовується метод за допомогою «змішування» поточного кадру з моделлю фону з коефіцієнтом а (a=0,05 [5]), потім до різниці фону і кадру застосовується пороговий фільтр. Цей метод також дуже простий у реалізації і має високу продуктивність, але він не вирішує проблему динамічного заднього плану.

На рис. 3 можна побачити моделювання цих методів у програмі MatLab. Усі методи чутливі до зміни світла та наявності тіней, що можна побачити на останньому зображенні (рис. 3). Тому була опробувана модифікація двох методів. Але в результаті подібного «з'єднання» виникала інша проблема зі слідом змішування рухомих об'єктів на фон при оновленні фону. Щоб уникнути цього, просто оновлювалася та частина, в якій немає цілі, а інша залишалась незмінною. При цьому об'єкти переднього плану віддалялися в модель фону.

\section{5. Апробація результатів досліджень}

Для моделювання застосовано програмний пакет MatLab. Використано відеозаписи розпуску відчепів на сортувальній гірці Одеса-сортувальна. Запис вівся стаціонарною камерою, установленою на освітлювальній щоглі. Сектор відеофіксації - другий пучок, спускна частина гірки. Використано камеру Canon D600, формат відеофрагментів mpeg4 3 наступним перекодуванням у формат avi.
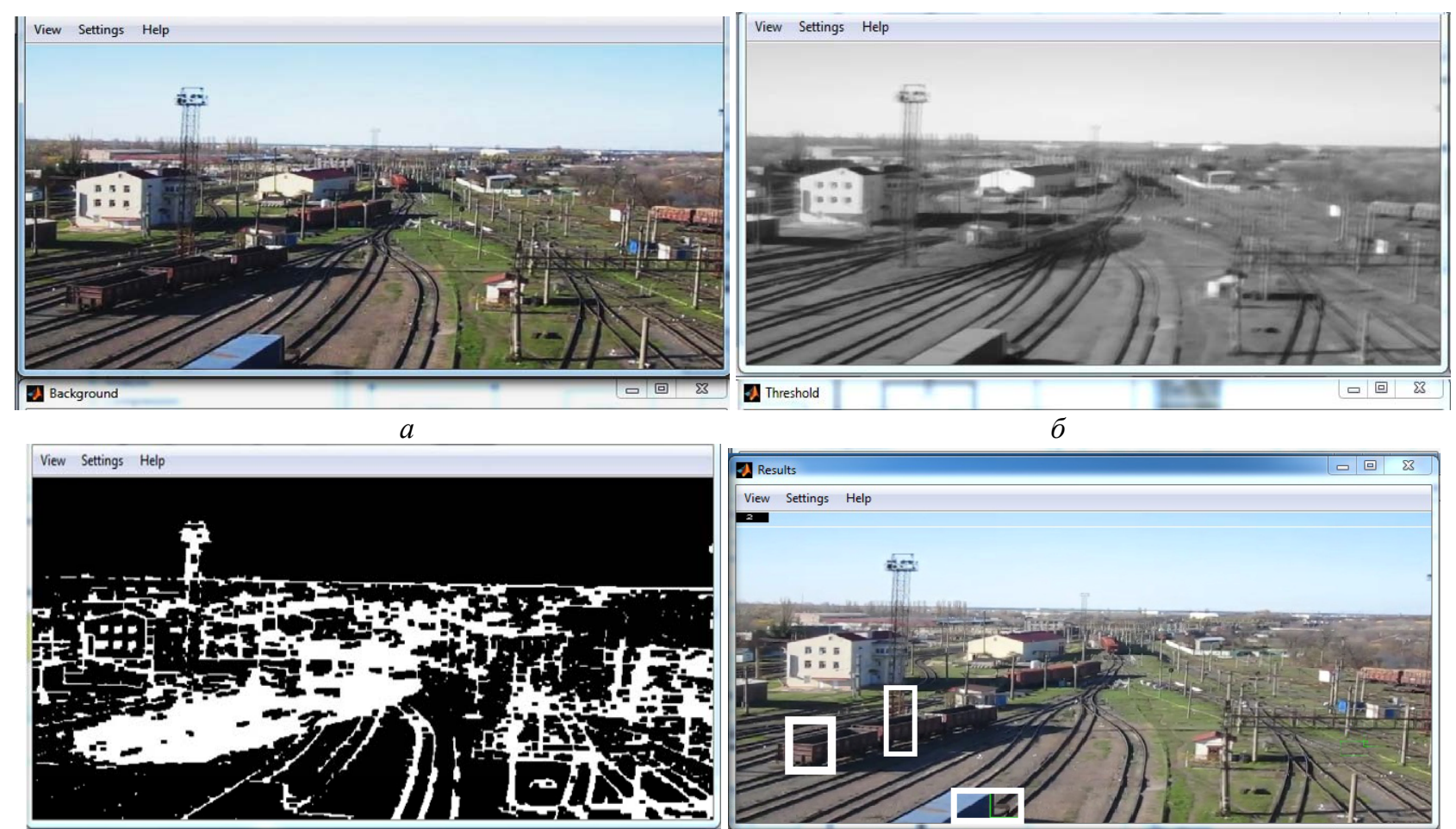

B

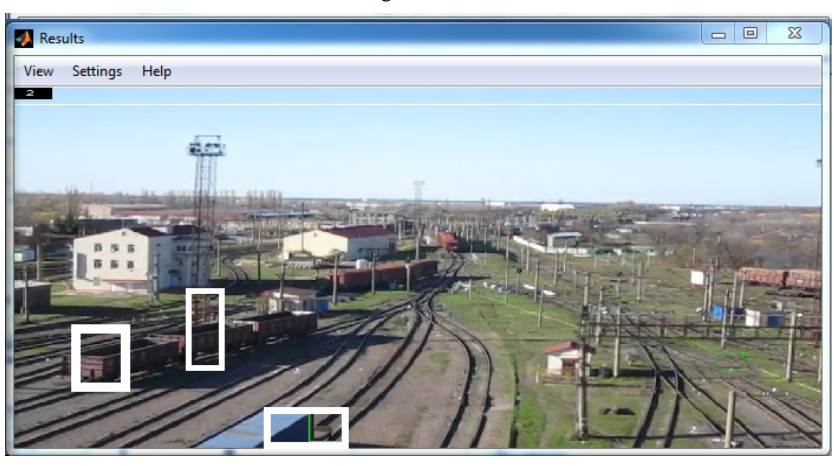

2

Рис. 3. Моделювання методом відніманя фону в програмному пакеті MatLab: $a$ - вихідне зображення; $\sigma$ - напівтонове зображення фону (початковий кадр); в - бінарне зображення фону (початковий кадр); 
На відео зафіксовано розпуск 47 відчепів, до яких входили напіввагони, вагони та цистерни. Найменший відчеп мав один вагон, найдовший - чотири. 3 використанням методу віднімання фону автоматично виявлено 49 об'єктів, що рухались. 3 них 39 відчепів, інші ідентифіковані об'єкти виявилися тінями та живими істотами.

\section{6. Висновки}

В результаті досліджень методів виявлення руху на сортувальних гірках визначено чотири основні методи, що найбільш доцільно використовувати для задачі, що розглядається. До них належать: метод виділення фону, метод міжкадрової різниці, метод віднімання фону, метод моделювання фону.

Розглянуто особливості застосування методу віднімання фону для виявлення руху відчепів на сортувальних гірках, що дало змогу визначити алгоритми застосування методу, за допомогою яких можливо створити багатофункціональну систему відстеження вагонів, здатну вести врахування і виявлення необхідних змін в умовах аналізу відеозображення спускної частини сортувальної гірки.

За допомогою програмного пакета MatLab проведено моделювання, яке дало змогу отримати кількісні характеристики застосування методу віднімання фону в межах розглянутих практичних задач.

\section{Література}

1. Иванов, Ю. А. Технологии компьютерного зрения в системах автоведения [Текст] / Ю. А. Иванов // Автоматика, связь, информатика. - 2011. - № 6. - С. 46-48.

2. Гасимов, Р. Ч. Программный комплекс для видеомониторинга железнодорожного переезда [Текст] : сборник докладов / Р. Ч. Гасимов // Научная сессия ГУАП, СанктПетербург (апр.2011). Ч. 2. Технические науки. - 2011. C. $10-12$.

3. Иванов, Ю. А. Технологии компьютерного зрения для наблюдения за объектами путевой инфраструктуры [Текст] / Ю. А. Иванов // Пром. трансп. XXI. - 2011. № 5-6. - C. 35-38.

4. Rodrigues, T. M. A novel approach to rail crossing protection using computer vision and radio communications [Text] / T. M. Rodrigues // Graph. And Vision. - 2011. - Vol. 20, Issue 1. - P. 41-71.

5. Иванов, Ю. А. Технологии компьютерного зрения [Текст] / Ю. А. Иванов // Железнодорожный транспорт. 2012. - № 12. - С. 49

6. Полоник, В. С. Телевизионная автоматика [Текст] / В. С. Полоник // Телевизионная автоматика. - 1970. № 5 . - C. 80 .

7. Костяшкин, Л. Н. Технологии систем улучшенного синтезированного зрения для управления летательными апаратами [Текст] / Л. Н. Костяшкин, С. И. Бабаев, А. А, Логинов, О. В. Павлов / Федеральное государственное унитарное предприятие «Государственный рязанский приборный завод» (ФГУП «ГРПЗ») Государственное образовательное учрежде- ние высшего профессионального образования «Рязанский государственный радиотехнический университет» (ГОУ ВПО «РГРУ»). - С. 27-34.

8. Блажевич, С. В. Автоматическое выделение и сопровождение псевдоточечных мерцающих объектов в реальном времени [Текст] / С. В. Блажевич, В. Н. Винтаев, H. Н. Ушакова. - Белгородский государственный университет (БелГУ), Белгородский университет потребительской кооперации (БУПК). - С. 44-50.

9. Shapiro, L. M. Computer Vision [Text] / L. M. Shapiro, J. P. Stockman // Knowledge Laboratory. - 2006. - Vol. 2. P. 752.

10. Форсайт, Д. Компьютерное зрение. Современный поход [Текст] / Д. Форсайт, Ж. Понс. - Издательский дом "Вильямс", 2004. - 197 с.

11. Nagy, A. T. Super-Resolution for Traditional and Omnidirectional Image Sequences [Text] / A. T. Nagy, Z. M. Vamossy // John von Neumann Faculty of Informatics / Institute of Software Technology. - 2007. - P. 117-129.

\section{References}

1. Ivanov, Y. A. (2011). Dispergirovannaya mikrokristallicheskaya celljuloza $i$ gidrogeli na ee osnove [Dysperhyrovannaya microcrystalline cellulose and Hydrogel Bases]. Chemistry vegetable raw materials, 2, 11-16.

2. Gasimov, R. Ch. (2011). Programnyy kompleks dlya videomonitoringa zheleznodorozhnogo pereezda. Nauchnaya sessiya GUAP, Sankt-Peterburg - apr.2011. Sbornik dokladov. Part 2. Tekhnicheskie nauki, 10-12.

3. Ivanov, Yu. A. (2011). Tekhnologii komp'yuternogo zreniya dlya nablyudeniya za ob"ektami putevoy infrastrkutury. Prom. transp.KhKhI, 5-6, 35-38.

4. Rodrigues, T. M. (2011). A novel approach to rail crossing protection using computer vision and radio communications. Graph. And Vision, 20 (1), 41-71.

5. Ivanov, Yu. A. (2012). Tekhnologii komp'yuternogo zreniya. Zheleznodorozhnyy transport, 12, 49

6. Polonik, V. S. (1970). Televizionnaya avtomatika. Televizionnaya avtomatika, 80 .

7. Kostyashkin, L. N., Babaev, S. I., Loginov, A. A., Pavlov, O. V. Tekhnologii sistem uluchshennogo sintezirovannogo zreniya dlya upravleniya letatel'nymi apparatami. Federal'noe gosudarstvennoe unitarnoe predpriyatie «Gosudarstvennyy ryazans'kiy pribornyy zavod» (FGUP «GRPZ») Gosudarstvennoe obrazovatel'no uchrezhdenie vysshego professional'nogo obrazovaniya «Ryazanskiy gosudarstvennyy radiotekhnicheskiy universitet» (GOU VPO «RGRU»), 27-34.

8. Blazhevich, S. V., Vintaev, V. N., Ushakova, N. N. Avtomaticheskoe vydelenie i soprovozhdenie psevdotochechnykh mertsayushchikh ob"ektov $\mathrm{v}$ real'nom vremeni. Belgorodskiy gosudarstvennyy universitet (BelGU), Belgorodskiy universitet potrebitel'skoy koopertsii (BUPK), 44-50.

9. Shapiro, L. M., Stockman, J. P. (2006). Computer Vision. Knowledge Laboratory, 2, 752.

10. Forsayt, D., Pons, Zh. (2004). Komp'yuternoe zrenie Sovremennyy pokhod. Izdatel'skiy dom "Vil'yams", 197.

11. Nagy, A. T., Vamossy, Z. M. (2007). SuperResolution for Traditional and Omnidirectional Image Sequences. John von Neumann Faculty of Informatics. Institute of Software Technology, 117-129.

Сіроклин Іван Миколайович, кандидат технічних наук, доцент, кафедра автоматики та комп'ютерного телекерування рухом поїздів, Українська державна академія залізничного транспорту, пл. Фейєрбаха, 7, м. Харків, Україна, 61050

E-mail: seroklin_iv@mail.ru 
Фоміна Валерія Олексіївна, кафедра «Спеціалізовані комп’ютерні системи», Українська державна академія залізничного транспорту, пл. Фейєрбаха, 7, м. Харків, Україна, 61050

E-mail: lerafomin@ukr.net

Бражник Андрій Анатолійович, кафедра «Спеціалізовані комп’ютерні системи», Українська державна академія залізничного транспорту, пл. Фейєрбаха, 7, м. Харків, Україна, 61050

E-mail: BrazhnikAA@gmail.com

УДК 656.073.235

DOI: $10.15587 / 2313-8416.2015 .35896$

\title{
ТЕХНОЛОГІЇ І ТЕХНІЧНІ ЗАСОБИ КОМБІНОВАНИХ ПЕРЕВЕЗЕНЬ ВАНТАЖІВ ЗА ЧИННИКАМИ ГЛОБАЛЬНОЇ ЛОГІСТИКИ
}

\author{
(C) А. М. Котенко, А. В. Світлична, П. С. Шилаєв
}

Враховуючи основні задачі глобальної логістики була розроблена і представлена нова контрейлерна технологія, яка дозволяє виконувати вантажні операції (навантаження та розвантаження модулів на платформи різної висоти підлоги від рівня головок рейок) та перевантажувати модулі з платформи на платформу з різною величиною міжрейкової колії та різною висотою підлоги платформ. Наведена система диференціальних рівнянь Колмогорова і виконано моделювання комбінованих перевезень

Ключові слова: контрейлерна технологія, комбіновані перевезення, глобальна логістика, диференціальні рівняння

The new piggybacks technology has been developed and presented taking into account the problems of global logistics. The technology allows cargo operations (loading and unloading of modules on platforms of varying floor height above rail head level) and reload modules between platforms with different values and different ways between rails floor height platforms. The system of differential equations of Kolmogorov have been showed and modeling of combined transportation have been made

Keywords: piggyback technology, combined transportation, global logistics, differential equations

\section{1. Вступ}

Одним з головних напрямків транспортної політики Свропейського Союзу в останні роки став розвиток системи комбінованих (контрейлерних) перевезень вантажів, що передбачає на основі логістичних принципів роботу суцільних транспортних ланцюгів як єдиного «перевізного конвеєра». Міжнародна практика свідчить, що більше третини всіх міжнародних вантажних перевезень, здійснюваних за принципом «від дверей до дверей», виконуються за допомогою контейнерних поїздів. При виборі найбільш пріоритетних напрямків розвитку транспортної галузі уряди європейських країн надають особливого значення забезпеченню чистоти атмосфери, схоронності екології навколишнього середовища від шкідливих викидів, забезпеченню безпеки життєдіяльності людей.

\section{2. Постановка проблеми}

Контрейлерні перевезення - один з основних видів інтермодальних вантажоперевезень на сьогоднішній день. Такий вид перевезень сприяє розвитку глобальної логістики в Україні. Метою логістичного рішення у глобальній логістиці є оптимізація руху матеріальноінформаційно-фінансових потоків на підприємстві шляхом забезпечення ефективного управління виробництвом, транспортом, відносинами 3 логістичними центрами, митницею, використання інформаційних систем підтримки прийняття рішень та сучасних технологій. Саме глобальні логістичні підходи уможливлюють знаходити найефективніші шляхи і форми руху матеріальних ресурсів на світовому ринку, а також забезпечують глибоку інтеграцію економіки держави у систему світогосподарських зв'язків. Вони включають комплекс послуг з доставки вантажів за допомогою автомобільного та залізничного транспорту (рис. 1).

Найбільш поширена схема здійснення таких перевезень передбачає закріплення автомобільних причепів, напівпричепів або цілого автопоїзда на залізничних платформах для подальшого транспортування. Велику частину шляху автомобільний транспорт знаходиться на залізничній платформі і тільки незначну долає «на колесах».Впровадження системи контрейлерних перевезень як підвищення ефективності логістичних схем загальносвітова тенденція. В Свропі планується до 2030 року переорієнтувати 30 \% всіх існуючих автомобільних вантажопотоків на залізничний транспорт. А до 2050 року до $50 \%$.

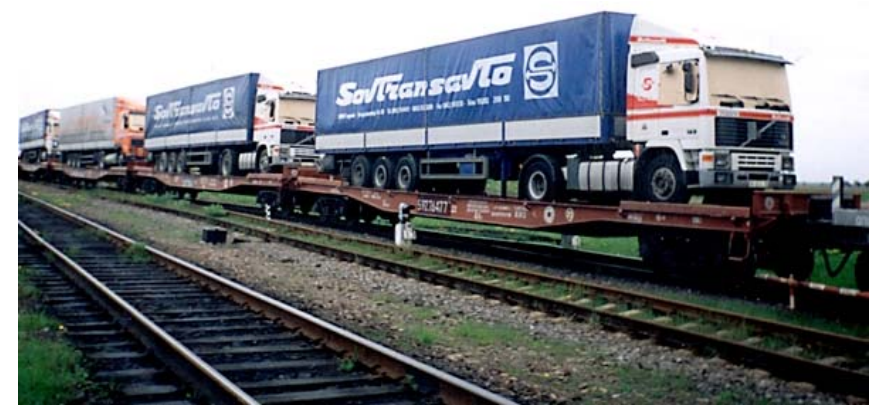

Рис. 1. Маршрут вантажних модулів на залізничній платформі

Протягом 2013 року залізниці України перевезли 443601.5 тис. т. вантажів, що на 3.02 \% менше, ніж у 2012 року. Тому стає необхідним вирішення питання 